\title{
Dieback and expansions: species-specific responses during 20 years of amplified warming in the high Alps
}

\author{
Klaus Steinbauer $^{1}$ (I) $\cdot$ Andrea Lamprecht $^{1} \cdot$ Philipp Semenchuk $^{2} \cdot$ Manuela Winkler $^{1} \cdot$ Harald Pauli $^{1}$
}

Received: 8 July 2019 / Accepted: 7 November 2019 / Published online: 20 November 2019

(C) The Author(s) 2019

\begin{abstract}
The largest alpine-nival vegetation permanent plot site in the Alps, the GLORIA mastersite Schrankogel (Tirol, Austria), provided evidence of warming-driven vegetation changes already 10 years after its establishment in 1994. Another decade later, in 2014, substantial compositional changes with increasing ratios of warmth-demanding to cold-adapted species have been found. The current study deals with species-specific responses involved in an ongoing vegetation transformation across the alpine-nival ecotone on Schrankogel by using presence/absence as well as cover data from permanent plots, situated between 2900 and 3400 masl. The number of occupied plots per species remained constant or even increased during the first decade, whereas disappearance events became more frequent during the second one, especially for cold-adapted specialists (subnival-nival species). Remarkably, the latter was accompanied by continued strong losses in cover of all subnival-nival species. These losses were more frequent in plots with a more thermophilous species composition, suggesting an increasing maladaptation of subnival-nival species to warmer habitat conditions and a successive trailing-edge decline. Several species with a distribution centre at lower elevations (alpine-subnival) markedly increased in cover, comparatively more so in colder plots, indicating a leading-edge expansion. Moreover, our findings show an increase in occupied plots and cover of almost all snowbed species, suggesting that areas previously with a too long snowpack period are now becoming suitable snowbed habitats. Vegetation gaps arising from population dieback of cold-adapted species, however, could only be partly filled by advancing species, indicating that species declines have occurred already before the onset of strong competition pressure.
\end{abstract}

Keywords Alpine $\cdot$ Biodiversity $\cdot$ Climate change $\cdot$ Ecotone $\cdot$ Migration $\cdot$ Nival $\cdot$ Schrankogel $\cdot$ Species

Klaus Steinbauer and Andrea Lamprecht contributed equally.

Electronic supplementary material The online version of this article (https://doi.org/10.1007/s00035-019-00230-6) contains supplementary material, which is available to authorized users.

Klaus Steinbauer

klaus.steinbauer@oeaw.ac.at

1 GLORIA Coordination, Institute for Interdisciplinary Mountain Research, Austrian Academy of Sciences \& Department of Integrative Biology and Biodiversity Research, University of Natural Resources and Life Sciences Vienna, Silbergasse 30/3, Vienna 1190, Austria

2 Department of Botany and Biodiversity Research, University of Vienna, Vienna 1030, Austria

\section{Introduction}

Cold-adapted mountain plant species are expected to suffer severe area losses because of warming-driven upward range shifts into high-elevation zones where space is limited (Engler et al. 2011; Freeman et al. 2018; Lenoir and Svenning 2015). However, revisitation studies of historical sites most commonly show increases in species numbers (Erschbamer et al. 2011; Grabherr et al. 1994; Grytnes et al. 2014; Walther et al. 2005; Wipf et al. 2013). A pan-European study found that the increase in species richness on summits was highly synchronous with warming trends and was related to climate-sensitive plant functional traits of alpine to subnival species in all European study regions. In contrast, changes in patterns of precipitation and nitrogen deposition did not or only regionally coincide with increasing plant diversity (Steinbauer et al. 2018). The congruency of the acceleration of warming with species accumulation rates thus reinforced the hypothesis that warming is the primary driver of upward 
shifting leading range margins of species. This finding is remarkable, however, with respect to the known slow growth rates of most high mountain plants (Körner 2003). Although model projections forecast reductions of suitable alpine habitats (Engler et al. 2011), refined models suggested delayed responses to warming due to the capability of long-lived alpine species to persist even in unsuitable habitats until life spans of resident individuals are reached (Cotto et al. 2017; Dullinger et al. 2012). This might explain why evidence of increasing species numbers through colonisation events, so far, outweighs observations of species declines. Alternatively, however, this imbalance may also reflect the scarcity of data from old enough permanent plots with information on species' abundances and/or their distribution across their entire vertical ranges.

A study comparing vegetation relevés dating back at least 45 years with recent surveys across the Eastern Alps showed that trailing edges are shifting at least as fast as leading edges and that both are ascending faster the lower they are situated (Rumpf et al. 2018). Given the conical shape of mountain summits, this could lead to a rapid narrowing of species ranges (Bertuzzo et al. 2016). Changes in the abundance of species even showed stronger signals compared to range shifts (Rumpf et al. 2018). Indeed, shifting abundances, such as in-filling or declines of resident populations, should be more immediate responses than actual shifts of their distribution ranges, given the high stochasticity involved in dispersal and recruitment of plant species (Giménez-Benavides et al. 2018) and the commonly rather long time until populations of perennial alpine species will have disappeared completely.

High-elevation plant assemblages above the closed grassland of the alpine zone should be especially useful for elucidating species-specific climate change effects, because they are less affected by biotic interactions and human land use, and species are highly adapted to low-temperature conditions. Data from the largest high-alpine to nival permanent plot site in the Alps (Schrankogel in the central Tyrolean Alps), comprising several hundred $1 \mathrm{~m}^{2}$ permanent plots, provided one of the first evidence of declining species covers already a decade after its setup in 1994 (Pauli et al. 2007). A repeated survey in 2014 showed thermophilisation effects of the same magnitude as the European average (Gottfried et al. 2012), which significantly accelerated in the recent decade (Lamprecht et al. 2018). Although this shift was accompanied by a net increase in species richness, the gain in species numbers slowed down due to species disappearances from the permanent plots, which were almost exclusively observed in the recent decade (Lamprecht et al. 2018).

In the light of the observed alteration of community composition and shifting balances of species gains and losses, we here focus on responses on the species level, i.e. we evaluate whether species adapted to high-elevation climates (subnival-nival species) respond consistently differently from species with lower distribution optima (alpine-subnival species). The focus on the level of individual species should enable to discern if species of similar vertical distribution show consistent response patterns and to contribute to a vulnerability assessment of high mountain plant species in the context of future conservation strategies.

Specifically, we ask:

(i) Do the dynamics of colonisation and disappearance events reflect homogenous tendencies within each species group (i.e. predominantly alpine-subnival species and subnival-nival species)?

(ii) Do cover increases of alpine-subnival species and cover decreases of subnival-nival species constitute to ongoing trends?

(iii) Do subnival-nival species decrease more pronouncedly in warmer plots and less in colder plots and vice versa for alpine-subnival species and therefore indicate gains at leading edges and losses at trailing edges?

\section{Methods}

The study site Schrankogel (3497 m; Stubaier Alpen, Tyrol, Austria) is located in the eastern central Alps within the protected area "Ruhegebiet Stubaier Alpen" (IUCN category IV). It is part of the Long-Term Socio-economic and Ecosystem Research (LTSER) platform Tyrolean Alps (Mirtl et al. 2015) and the Global Observation Research Initiative in Alpine Environments (GLORIA, http://www.gloria.ac. at). The bedrock is composed of siliceous material, mostly amphibolite and gneiss (Hammer et al. 1929). Annual precipitation sum at the closest nival observatory (Sonnblick $3109 \mathrm{msl}, 200 \mathrm{~km}$ east of Schrankogel) ranged between 1400 and $2300 \mathrm{~mm}$ in the period 1991-2014. Mean monthly air temperature of June, July and August at Brunnenkogel (3440 msl, located $30 \mathrm{~km}$ southwest of Schrankogel) varied roughly between -2.9 and $3.9{ }^{\circ} \mathrm{C}$ between 2004 and 2014 (Zentralanstalt für Meteorologie und Geodynamik, http:// www.zamg.ac.at).

\section{Vegetation sampling and dataset}

With the intention of detecting climate-driven vegetation changes, around $10001 \mathrm{~m}^{2}$ permanent plots were established along the southwest to east facing slope system of Schrankogel in 1994 (Lamprecht et al. 2018). Plots were arranged in transects which were grouped in four spatially divided blocks (Fig. S1). Field sampling comprised the visual estimation of the percentage cover of surface types (solid rock, scree, bare ground and vegetation) and of each 
vascular plant species present in a permanent plot, where a cover of $1 \%$ refers to $1 \mathrm{dm}^{2}$. Resurveys of the permanent plots were conducted in 2004 (362) and 2014 (661 plots). Plots with high disturbance due to rockfall were excluded, leaving 355 plots in 2004 and 654 in 2014. Two datasets were compiled for further analysis: (1) A dataset comprising 654 permanent plots for changes across a time span of 20 years (1994 to 2014; dataset-2s), and (2) a smaller subset of 355 permanent plots, where data available from all three surveys (1994, 2004 and 2014; dataset-3s) allowed for the comparison among the two decades. Species names follow Fischer et al. (2008) except for Senecio incanus subsp. carniolicus where we used Senecio carniolicus agg. (Flatscher et al. 2015).

\section{Statistical analyses}

All statistical analyses were performed using the statistic software R version 3.5.0 (R Core Team 2018) and figures were created with ggplot2 (Wickham 2016). Generalised linear mixed effects models (GLMMs) were fitted to analyse changes in the number of occupied plots (presence/absence) and cover across the surveys in both datasets and colonisations and disappearances in dataset- $3 \mathrm{~s}$ in the two decades for each species. To reflect the spatial structure of the dataset, plot nested in transect nested in block was included as random intercept term in all models. Only species present in at least 30 plots and with at least ten colonisations or disappearance events were analysed individually. Hypothesis testing of all models was conducted by a simultaneous inference procedure implemented in function glht from the multcomp package (Hothorn et al. 2008). Model diagnostic graphs were checked visually for outliers, homogeneity of variance and independence of residuals. Outliers were subsequently removed. The annual Euphrasia minima was excluded from analysis, because it shows high inter-annual fluctuations both in occurrence and abundance (Table S1), which may reflect shorter-term weather conditions over one or two seasons rather than longer-term climatic changes (Lamprecht et al. 2018).

To analyse differences in the number of occupied plots (presence/absence) between the surveys and differences in colonisations and disappearances between the decades 1994-2004 and 2004-2014 for each species, GLMMs (function glmer from package lme4) assuming a binomial error distribution were used (Bates et al. 2015; Kuznetsova et al. 2016; Mangiafico 2018). A species' presence (1)/absence (0) in each plot was used as response and year as fixed. For colonisations and disappearances, the binary response variable was set to 1 if a species had colonised or disappeared from a plot, respectively, and to 0 if this was not the case. Decade was used as fixed effect. A colonisation event is defined as absence in year $r_{t}$ and presence in year $r_{t+10}$ of a given species in a given permanent plot. A disappearance event occurs when a species was present in a given permanent plot in year $_{\mathrm{t}}$ and absent in year ${ }_{t+10}$. Only plots which could potentially be colonised (i.e. where a species was not present in year $r_{t}$ ) or from which a species could potentially disappear (i.e. where a species was present in year ${ }_{t}$ ), respectively, were used. For Gnaphalium supinum and Sagina saginoides with no disappearance events in one decade, a negative binomial distribution was assumed, as the binomial GLMM did not converge due to a singular fit.

To analyse differences in species cover, all plots with a species present in at least one survey year were considered. Absent species were assigned a cover value of zero. As both datasets were heteroscedastic and asymmetric, we used GLMMs (function glmmTMB; Brooks et al. 2017) with a standard beta distribution (Cribari-Neto and Zeileis 2010) and year as fixed effect. Percentage cover of each species $(y)$ within an interval of zero and one, where one represented the maximal possible value of $100 \%$, was subsequently compressed to bound data away from zeros and ones. This was conducted according to Smithson and Verkuilen (2006) by

$y^{\prime}=\frac{(y(N-1)+0.5)}{N}$,

where $N$ is the sample size. In dataset-2s, the assumption of independence in the residuals was violated in the case of Arenaria ciliata, Minuartia sedoides and Poa alpina and a negative binomial distribution was chosen instead.

Altitudinal ranks (ARs) are classifications of species according to their distributions along an altitudinal gradient ranging from subnival-nival $(\mathrm{AR}=1)$ to subalpine-alpine $(\mathrm{AR}=4)$. A community-weighted thermic indicator $(\mathrm{TI})$ for each plot and survey year was calculated based on each species' AR classification and weighted by its relative cover:

$\mathrm{TI}=\left(\sum \mathrm{AR}\left(\right.\right.$ species $\left.\left.\left._{i}\right) \times \operatorname{cover}_{\left(\text {species }_{i}\right.}\right)\right) / \sum \operatorname{cover}\left(\operatorname{species}_{i}\right)$.

The TI of the permanent plots on Schrankogel was shown to be highly correlated with soil temperature (Lamprecht et al. 2018) and was previously used as an indicator of temperature conditions (e.g. Gottfried et al. 2012).

To show changes in cover sum of AR species groups and of individual species across a temperature gradient between 1994 and 2014, the TI of the baseline year 1994 $\left(\mathrm{TI}_{94}\right)$ of each permanent plot in dataset-2s was used as a proxy for thermal conditions where $\mathrm{TI}_{94}=1$ refers to subnival-nival and $\mathrm{TI}_{94=} 3$ to alpine conditions. Differences in cover between 1994 and 2014 across the $\mathrm{TI}_{94}$-gradient for each AR were analysed using GLMMs assuming a beta distribution. Cover was used as response, the interaction of $\mathrm{TI}_{94}$ and year as fixed effect and species as second random effect. Function ggpredict was used to plot model predictions (Lüdecke 2018). 


\section{Results}

In dataset-2s (654 plots) and dataset-3s (355 plots), 72 and 63 vascular plant species were present, respectively, during the study period (Table S1). Eighteen species were recorded only in 2014 and two species only in 1994.

\section{Changes in the number of occupied plots}

The number of occupied plots increased for most of the species between 1994 and 2014 (dataset-2s). Thirty out of 40 modelled species increased significantly, including 1 AR1 $(P<0.0001), 15$ AR2 $(P<0.02), 11$ AR3 $(P<0.01)$ and 3 AR4 species $(P<0.0001$; GLMMs, Table 1, Tables S1, S2). The number of occupied plots decreased only in the AR1 species Poa laxa $(P<0.0001)$. Five out of nine snowbed species, associated with AR2 and AR3, showed an increasing tendency $(P<0.0001)$. Six AR3 and 12 AR4 species, respectively, were found for the first time in the plots in 2014. Significant changes in the number of occupied plots were increases in both decades for almost all AR2 and AR3 species, whereas AR1 species showed increases only in the first and decreases in the second decade (dataset-3s; Table S3).

\section{Changes in colonisations and disappearances (dataset-3s)}

Colonisation rates increased significantly for Festuca intercedens $(P=0.001 ; \mathrm{AR} 2)$ and Sibbaldia procumbens $(P=0.001$; AR3) between 1994-2004 and 2004-2014 (Table S4). In contrast, Androsace alpina and Ranunculus glacialis $(P<0.03$; AR1), as well as Gnaphalium supinum, Sagina saginoides and Sedum alpestre $(P<0.03$; AR3) showed significantly fewer colonisation events in the period 2004-2014. In the second decade, significantly more disappearances were recorded in four AR1 $(P<0.01)$, five AR2 $(P<0.01)$ and six AR3 species $(P<0.03$; Table S5).

\section{Changes in species cover}

The cumulative cover of 13 species, including all 6 AR 1 species $(P<0.0001), 3$ AR2 $(P<0.01)$ and 4 AR3 species $(P<0.02)$ decreased significantly between 1994 and 2014 (datatset-2s; GLMMs; Table 1, Table S6). In contrast, none of the AR4 species decreased significantly. A significant increase in cover was observed in 16 species including 10 AR2 $(P<0.03), 4$ AR3 $(P<0.0001)$ and 2 AR4 species $(P<0.0001)$. Six snowbed species increased their cover significantly, only Sedum alpestre declined $(P<0.0001)$. Overall, Cerastium uniflorum, Poa laxa, Saxifraga bryoides (AR1) and Carex curvula (AR3) showed the strongest decrease and Pedicularis aspleniifolia, Silene exscapa and Veronica alpina (AR2) the strongest increase in total cover during the study period $(P<0.0001)$.

All AR1 species declined in both decades $(P<0.0001)$, except Saxifraga oppositifolia with a significant decrease only in the period 2004-2014 ( $P=0.001$; dataset-3s, GLMMs, Fig. 1a, d; Table S7). Two AR2 species (Pedicularis aspleniifolia and Silene exscapa) increased in both decades $(P<0.03)$, and three (Festuca intercedens, Saxifraga exarata and Trisetum spicatum) in only one decade $(P<0.04$; Fig. 1b, e; Table S7). In contrast, Gentiana bavarica decreased in both decades and Primula glutinosa only in the second decade $(P<0.04)$. The graminoid AR3 species Carex curvula and Poa alpina declined in one of the decades $(P<0.0001$; Fig. 1c, f, Table S7). The snowbed species Veronica alpina and Sibbaldia procumbens increased in both decades $(P<0.04)$, while Sedum alpestre decreased in both decades $(P<0.01)$, and Sagina saginoides increased in cover between 1994 and 2004 and decreased between 2004 and 2014 ( $P<0.0001$; Fig. 1b, c, e, f; Table S7).

\section{Species cover changes across a community-weighted thermic indicator gradient}

Cover sums of individual species (Fig. S2) and of AR species groups (Fig. 2) revealed considerable differences when comparing the patterns of 1994 and 2014 along the TI gradient of the baseline year ( $\mathrm{TI}_{94}$; Fig. 2; Fig. S2; Table S8). AR1 species had decreased considerably in cover over the entire $\mathrm{TI}_{94}$ gradient, which was slightly stronger in the warmer (alpine) plots ( $P=0.001$; Fig. 2e, Fig. S2; Table S8). In contrast, AR2 species became more abundant in colder (subnival-nival) plots with a $\mathrm{TI}_{94}<2(P<0.0001$; Fig. 2f; Table S8). Species of AR3 were initially more abundant in plots with a $\mathrm{TI}_{94}>2.4$, but changed significantly towards higher cover in colder and less cover in warmer plots in 2014 ( $P<0.001$; Fig. 2g; Table S8). The latter was mainly driven by cover losses of Carex curvula and Poa alpina (Fig. S2). AR4 species, on the contrary, expanded significantly, but uniformly in abundance over the entire $\mathrm{TI}_{94}$-gradient $(P=0.048 ;$ Fig. 2d, h, Fig. S2; Table S8).

\section{Discussion}

Data from permanent plots distributed across the alpine-nival ecotone on Schrankogel provided an early signal of climate change-driven plant species declines, already 10 years after the baseline was set in 1994 (Pauli et al. 2007). After adding the data from 2014, another decade later, the previously observed cover declines could be confirmed, along with a continued increase in species richness, although 
Table 1 Vascular plant species per altitudinal rank (AR) and their occurrences in 654 permanent plots across the alpine-nival ecotone on Schrankogel in 1994 and 2014 (dataset-2 s)

\begin{tabular}{|c|c|c|c|c|c|c|}
\hline \multirow[t]{3}{*}{ Altitudinal rank } & \multirow[t]{3}{*}{ Species } & \multicolumn{2}{|c|}{ Occupied plots } & \multirow{3}{*}{$\begin{array}{l}\text { Colonisation/ } \\
\text { disappearance } \\
N \\
1994-2014\end{array}$} & \multicolumn{2}{|l|}{ Cover } \\
\hline & & $N$ & $P$ value & & $\operatorname{Sum}\left(\mathrm{dm}^{2}\right)$ & $P$ value \\
\hline & & $1994 / 2014$ & 1994-2014 & & $1994 / 2014$ & 1994-2014 \\
\hline \multirow[t]{6}{*}{ AR1 } & Androsace alpina & $247 / 228$ & $\searrow$ & $51 / 70$ & $111.8 / 27.8$ & $\downarrow \downarrow \downarrow$ \\
\hline & Cerastium uniflorum & $440 / 444$ & ns & $51 / 47$ & $1401.8 / 643.4$ & $\downarrow \downarrow \downarrow$ \\
\hline & Poa laxa & $614 / 581$ & $\downarrow \downarrow \downarrow$ & $15 / 48$ & $1125.6 / 605.1$ & $\downarrow \downarrow \downarrow$ \\
\hline & Ranunculus glacialis & $478 / 479$ & ns & $54 / 53$ & 278.3/143.6 & $\downarrow \downarrow \downarrow$ \\
\hline & Saxifraga bryoides & $540 / 590$ & $\uparrow \uparrow \uparrow$ & $61 / 11$ & $2229.3 / 1650.3$ & $\downarrow \downarrow \downarrow$ \\
\hline & Saxifraga oppositifolia & $66 / 68$ & ns & $12 / 10$ & 193.3/127.4 & $\downarrow \downarrow \downarrow$ \\
\hline \multirow[t]{17}{*}{ AR2 } & Arenaria ciliata & $32 / 37$ & $\nearrow$ & $7 / 2$ & $21.0 / 19.2$ & ns \\
\hline & Cardamine resedifolia $^{\mathbf{s n}}$ & $17 / 63$ & $\uparrow \uparrow \uparrow$ & $50 / 4$ & $2 / 7.4$ & $\uparrow \uparrow \uparrow$ \\
\hline & Draba fladnizensis & $41 / 37$ & ns & $13 / 17$ & $2.6 / 1.4$ & $\downarrow \downarrow$ \\
\hline & Erigeron uniflorus & $192 / 317$ & $\uparrow \uparrow \uparrow$ & $133 / 8$ & $245.5 / 273.8$ & $\uparrow \uparrow \uparrow$ \\
\hline & Festuca intercedens & $124 / 218$ & $\uparrow \uparrow \uparrow$ & $107 / 13$ & $161.3 / 212.2$ & $\uparrow \uparrow \uparrow$ \\
\hline & Gentiana bavarica var. subacaulis & $298 / 335$ & $\uparrow \uparrow \uparrow$ & $56 / 19$ & $145.3 / 57.3$ & $\downarrow \downarrow \downarrow$ \\
\hline & Leucanthemopsis alpina & $504 / 577$ & $\uparrow \uparrow \uparrow$ & $81 / 8$ & 1171.9/1116.1 & $\mathrm{ns}$ \\
\hline & Luzula spicata & $445 / 523$ & $\uparrow \uparrow \uparrow$ & $101 / 23$ & $647.3 / 689.9$ & $\uparrow$ \\
\hline & Oreochloa disticha & $210 / 277$ & $\uparrow \uparrow \uparrow$ & $81 / 14$ & $515.5 / 532.4$ & $\uparrow$ \\
\hline & Pedicularis aspleniifolia & $32 / 92$ & $\uparrow \uparrow \uparrow$ & $63 / 3$ & $12.9 / 71.4$ & $\uparrow \uparrow \uparrow$ \\
\hline & Primula glutinosa & $281 / 306$ & $\uparrow$ & $50 / 25$ & $471.8 / 421.5$ & $\downarrow \downarrow$ \\
\hline & Saxifraga androsacea & $17 / 41$ & $\uparrow \uparrow$ & $34 / 10$ & $3.1 / 9.8$ & ns \\
\hline & Saxifraga exarata s.str. & $122 / 193$ & $\uparrow \uparrow \uparrow$ & $93 / 22$ & $70.8 / 113.1$ & $\uparrow \uparrow \uparrow$ \\
\hline & Saxifraga seguieri & $16 / 26$ & $\uparrow \uparrow$ & $19 / 9$ & $3.6 / 6.3$ & ns \\
\hline & Silene exscapa & $382 / 478$ & $\uparrow \uparrow \uparrow$ & $108 / 12$ & $1750.7 / 2418.6$ & $\uparrow \uparrow \uparrow$ \\
\hline & Trisetum spicatum & $27 / 79$ & $\uparrow \uparrow \uparrow$ & $57 / 5$ & $12.3 / 28.0$ & $\uparrow \uparrow \uparrow$ \\
\hline & Veronica alpina $^{\mathbf{s n}}$ & $113 / 235$ & $\uparrow \uparrow \uparrow$ & $122 / 0$ & $46.9 / 173.8$ & $\uparrow \uparrow \uparrow$ \\
\hline \multirow[t]{12}{*}{ AR3 } & Carex curvula & $109 / 122$ & $\uparrow \uparrow$ & $15 / 2$ & 1985.7/1381.1 & $\downarrow \downarrow \downarrow$ \\
\hline & Cerastium cerastoides $^{\mathbf{s n}}$ & $18 / 21$ & ns & $16 / 13$ & $2.4 / 9.7$ & $\nearrow$ \\
\hline & Gnaphalium supinum $^{\mathbf{s n}}$ & $69 / 227$ & $\uparrow \uparrow \uparrow$ & $161 / 3$ & $8.2 / 34$ & $\uparrow \uparrow \uparrow$ \\
\hline & Minuartia gerardii & $75 / 99$ & $\uparrow \uparrow$ & $41 / 17$ & $30.7 / 35.2$ & ns \\
\hline & Minuartia sedoides & $368 / 456$ & $\uparrow \uparrow \uparrow$ & $104 / 16$ & $1033.4 / 1028.9$ & $\mathrm{~ns}$ \\
\hline & Phyteuma hemisphaericum & $47 / 59$ & $\uparrow \uparrow$ & $15 / 3$ & $92.5 / 47.4$ & $\downarrow$ \\
\hline & Poa alpina & $176 / 244$ & $\uparrow \uparrow \uparrow$ & $90 / 22$ & $325.5 / 174.0$ & $\downarrow$ \\
\hline & Sagina saginoides ${ }^{\mathbf{s n}}$ & $40 / 117$ & $\uparrow \uparrow \uparrow$ & $90 / 13$ & $7.3 / 11.1$ & $\uparrow \uparrow \uparrow$ \\
\hline & Sedum alpestre ${ }^{\mathbf{s n}}$ & $191 / 241$ & $\uparrow \uparrow \uparrow$ & $71 / 21$ & $48.9 / 31.3$ & $\downarrow \downarrow \downarrow$ \\
\hline & Senecio carniolicus agg. & $20 / 34$ & $\uparrow \uparrow \uparrow$ & $16 / 2$ & $4.4 / 4.1$ & ns \\
\hline & Sibbaldia procumbens ${ }^{\mathbf{s n}}$ & $12 / 52$ & $\uparrow \uparrow \uparrow$ & $40 / 0$ & $4.8 / 22.6$ & $\uparrow \uparrow \uparrow$ \\
\hline & Veronica bellidioides & $25 / 55$ & $\uparrow \uparrow$ & $34 / 4$ & $23.8 / 58.1$ & $\uparrow \uparrow \uparrow$ \\
\hline \multirow[t]{2}{*}{ AR4 } & Avenula versicolor & $18 / 45$ & $\uparrow \uparrow \uparrow$ & $29 / 2$ & $48.5 / 118.7$ & $\uparrow \uparrow \uparrow$ \\
\hline & Potentilla aurea & $0 / 31$ & $\uparrow \uparrow \uparrow$ & $31 / 0$ & $0 / 4.1$ & $\uparrow \uparrow \uparrow$ \\
\hline
\end{tabular}

AR denotes a species' distribution range along the elevation gradient (after Gottfried et al. 2012). Shown are vascular plant species with significant differences either in the number of occupied plots or cover. $P$ values were derived from generalised linear mixed effects model with the number of occupied plots or cover as response, year or decade as fixed effect and plot nested in transect nested in block as random effect. For further details and all study species see Tab S1-S2, S6

NA, model not available; ns, not significant; $\uparrow$, increase; $\downarrow$, decrease; $\nearrow / \searrow, P=0.05-0.1 ; \uparrow / \downarrow, P=0.01-0.05 ; \uparrow \uparrow / \downarrow \downarrow, P=0.01-0.001 ; \uparrow \uparrow \uparrow / \downarrow \downarrow \downarrow$, $P<0.001$; AR1, subnival-nival; AR2, alpine-subnival; AR3, alpine; AR4, subalpine-alpine; sn, refers to snowbed species 


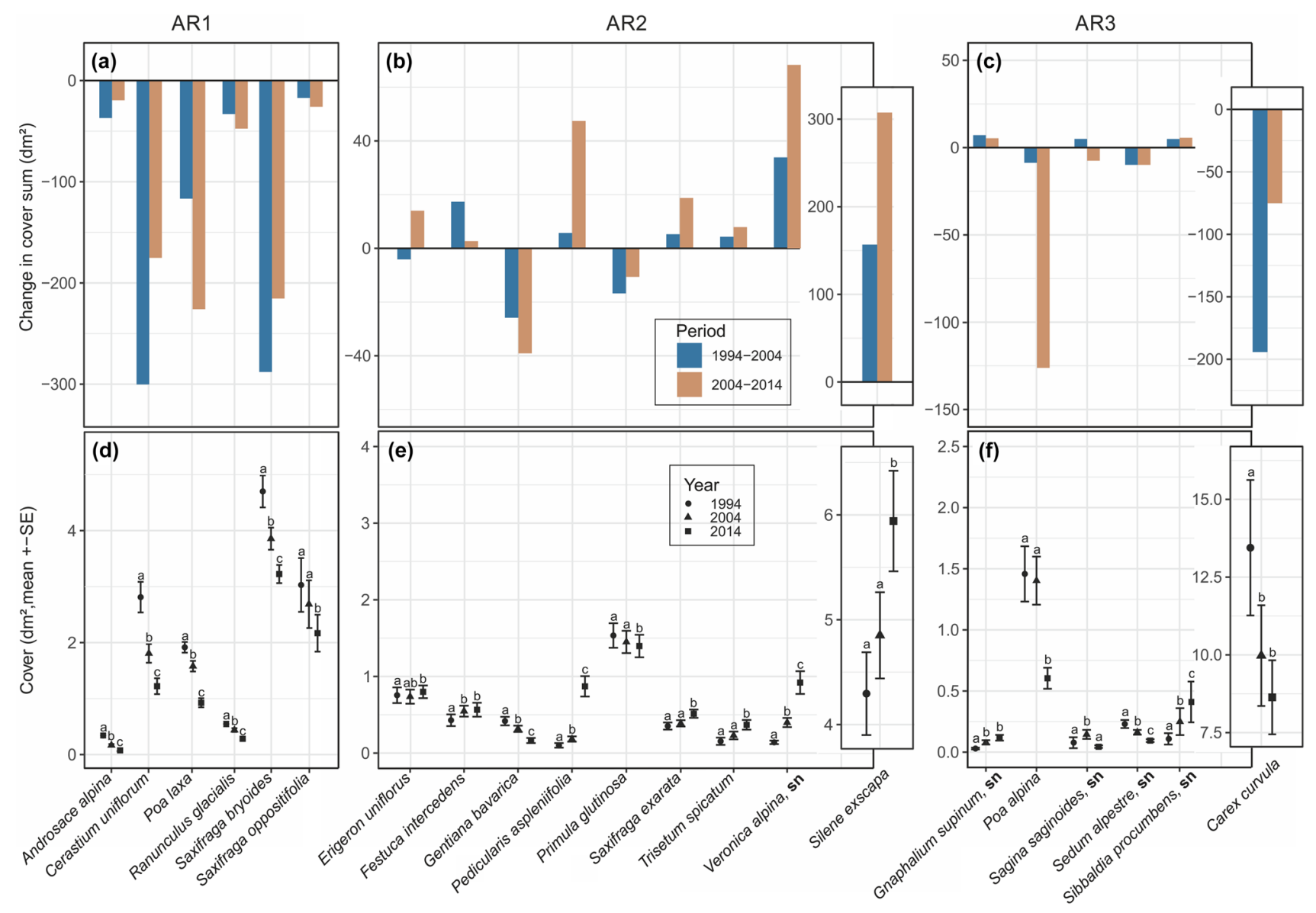

Fig. 1 Changes in cover values of vascular plant species on Schrankogel from 1994-2004-2014 (dataset-3s). Shown are changes in cover sum between the periods 1994-2004 and 2004-2014 (a-c) and mean cover values per plot \pm standard error (SE) in the years 1994, 2004 and 2014 (d-f). Only vascular plant species with significant differences grouped in altitudinal ranks (ARs) are shown. The AR denotes a species' distribution range along the elevation gradient (after Gottfried et al. 2012). AR1 (a, d) are subnival-nival, AR2 (b, e) alpine-subnival, and AR3 (c, f) alpine species. Lower-case letters denote significant differences between survey years. Note different scales for each AR as well as for Carex curvula and Silene exscapa. Snowbed species are indicated by sn. For details on raw data and significant differences see Tables S1 and S7

the 20 years of observation (Table 1, Tables S1-S5), corroborating recently found increases in species richness in other parts of the Alps (Erschbamer et al. 2011; Wipf et al. 2013) and on more than 300 mountain summits distributed across Europe (Grytnes et al. 2014; Pauli et al. 2012; Steinbauer et al. 2018).

Even though the high-elevation species group (AR1) showed both colonisations and disappearances (Table 1, Tables S1, S4, S5), colonisations became rarer and disappearances more frequent in the second decade. Such a decrease in the gain/loss ratio signals a trailing-edge contraction (i.e. trailing edge moving closer to the leading edge; Lamprecht et al. 2018). Propagation capabilities of at least some AR1 species, however, should be sufficient for reaching new habitats. Tackenberg and Stöcklin (2008) reported that seeds of Saxifraga bryoides can be transported more than $1000 \mathrm{~m}$ by wind. At the same time, observations of 

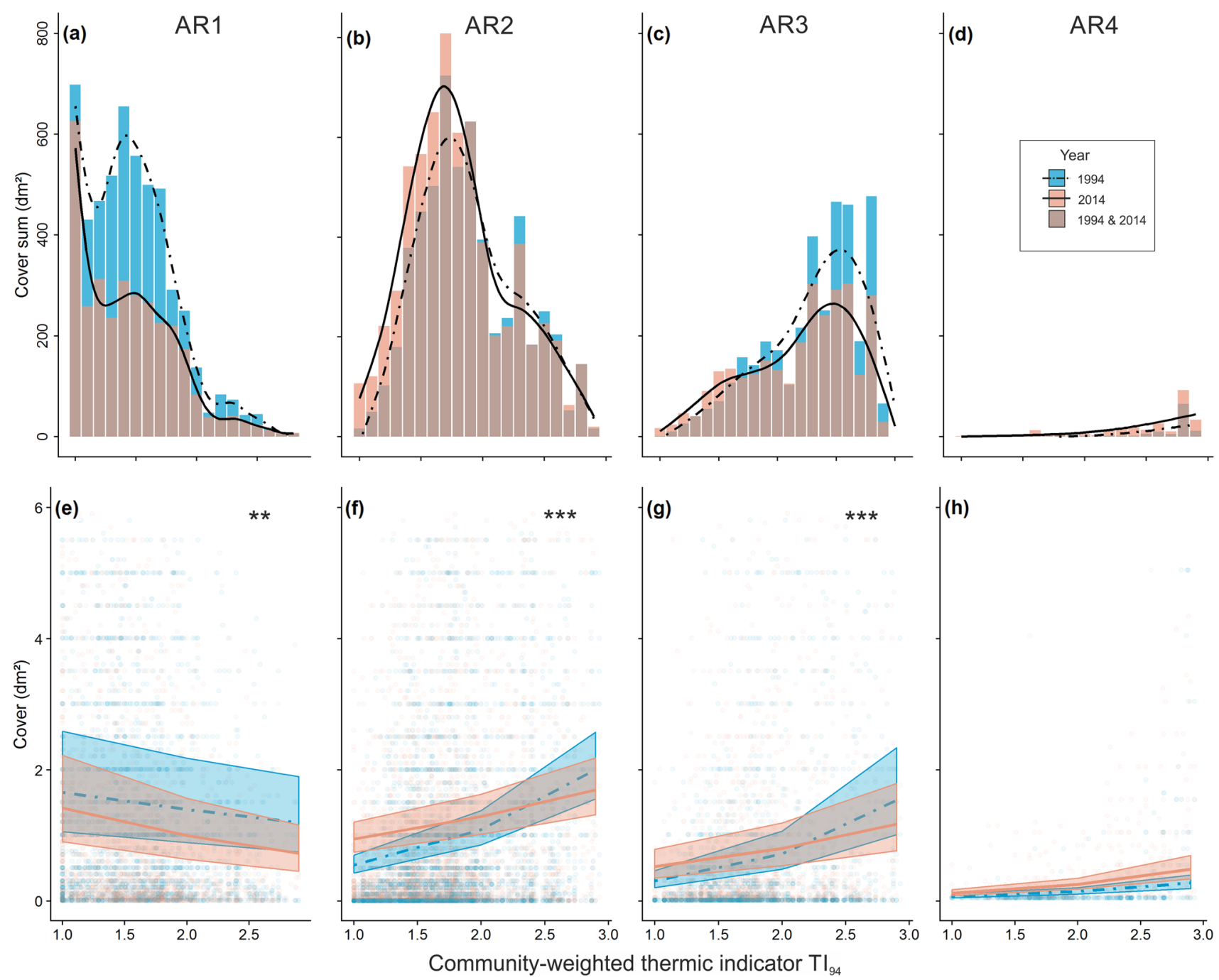

Fig. 2 Cover sum and cover per permanent plot of vascular plant species in different altitudinal ranks (AR) between 1994 and 2014 on 654 permanent plots on Schrankogel (dataset 2-s). The AR denotes a species' distribution range along the elevation gradient (after Gottfried et al. 2012). AR1 (a, e; $n=6$ ) denotes subnival-nival, AR2 (b, $\mathbf{f} ; n=21)$ alpine-subnival, AR3 (c, $\mathbf{g} ; n=23)$ alpine and AR4 (d, h; $n=22)$ subalpine-alpine species. All permanent plots were grouped following their community-weighted thermic indicator values of the baseline year $1994\left(\mathrm{TI}_{94}\right)$. These $\mathrm{TI}_{94}$-values ranged between 1.0 (subnival-nival plots) and 3.0 (alpine plots). A generalised additive model was used to fit smooth splines with cover sum as response and $\mathrm{TI}_{94}$ as

colonisation events are fairly unlikely, as most AR1 species already occupy a large number of plots, rendering the interpretation of decreasing colonisation events difficult (e.g. Cerastium uniflorum, Poa laxa, Ranunculus glacialis and Saxifraga bryoides are present in more than two-thirds of all plots; Table 1, Table S1).

Most of the AR2 species show a clear prevalence of colonisations over disappearances (Table 1, Tables S1, S4, S5), suggesting a leading-edge expansion of this species group, similar to previous observations of elevational and explanatory variable in each year (a-d). Cover of each AR in every plot and year was analysed using a generalised linear mixed effects model assuming a beta distribution (e-f). The interaction of $\mathrm{TI}_{94}$ and year was used as a fixed effect and plot nested in transect, nested in block as well as species were used as random effects. Shown are predicted values with a $95 \%$ confidence interval (lines) and raw data (points). *Significant differences between interaction of $\mathrm{TI}_{94}$ with year. For model details see Table S8. For details of cover sum of single species across the $\mathrm{TI}_{94}$-gradient, cf. Fig.S2. AR1 (a, e; $\left.n=6\right)$ denotes subnival-nival, AR2 (b, f; $n=21)$ alpine-subnival, AR3 (c, $\mathrm{g} ; \mathrm{n}=23)$ alpine and AR4 $(\mathbf{d}, \mathbf{h} ; n=22)$ subalpine-alpine species

latitudinal range shifts (Carilla et al. 2018; Parmesan and Yohe 2003; Rumpf et al. 2018). Among the common AR2 species, Silene exscapa exhibited a moderate but steady increase and hardly any losses, whereas others like Festuca intercedens showed contrasting changes with both numbers of colonisations and disappearances significantly increasing from the first to the second decade (Tables S1, S4, S5). Such varied fluctuations presumably reflect different ratios of successful/failed establishments, rather than trends in range expansion or contraction. Despite overall warming, late frost 
events or cold spells during summer continue to occur and can affect temperature-sensitive seedlings and young plants (Ladinig et al. 2013), which may have contributed to the observed variation in species occurrences.

Furthermore, 18 of the colonising species were new, i.e. not observed previously in any of the plots, whereas only 2 disappeared from the single plot they had previously occupied (Table S1). All newcomers were alpine or species from lower elevations (AR3, AR4), having shifted their upper ranges to the alpine-nival ecotone during two decades (1994-2014), most likely driven by strongly rising temperatures within this period (Chen et al. 2011; Marty and Meister 2012).

Generally, all common AR3 species show more colonisation than disappearance events, however, with some fluctuations among decades, e.g. for the short-lived Sagina saginoides, which exhibits annual behaviour and plentiful seed production (Tables S1, S5, S6; Cannone et al. 2008). The same was true within the AR4 group, which showed a strong increase in the number of occupied plots, although this group is so far rather negligible concerning the total number of plots.

Regarding research question $i$, we cannot confirm a consistent response pattern within ARs. While an overall increase of alpine-subnival (AR2) and lower elevational species could be detected, some species reacted in other ways. In contrast, although a decline of subnival-nival (AR1) species is visible most notably in the second decade, the overall signal obtained by presence/absence data is weak.

\section{The dieback of the cryophiles}

In contrast to presence/absence data, almost all high-elevation specialist species (AR1) showed a clear signal of cover reduction. This decrease in abundance was already found 10 years after the baseline survey (Pauli et al. 2007) and remained unbroken during the second decade across all AR1 species (Fig. 1 a, Table 1, Tables S1, S6, S7). This negative abundance change of resident species was to be expected as a first response to climate warming, as it reflects changes in growth performance. Range shifts, in contrast, do not only depend on climatic factors but also involve uncertainties of successful establishment. Evidence of abundance declines in alpine plants is scarce in the literature compared to the ample evidence of changing species numbers, as suitable long-term data series are lacking.

The few studies involving abundance records, indeed, found significant decreases of cold-adapted species: Lesica (2014) reported that species restricted to high elevations declined more than species with broader elevation amplitudes in the Montana Rocky Mountains between 1988 and 2011. In the alpine zone of the central Appenines, a revisitation study found decreasing abundances of cryophilic species after 42 years (Evangelista et al. 2016). A comparison of old plots (before 1970) with resurveys at nearby locations with similar habitat conditions showed that changes in abundance were stronger than shifts of lower and upper range margins, with above-average declines found for the high-elevation species (Rumpf et al. 2018).

Given that all AR1 species are perennial plants, the compelling evidence of their cover decrease suggests a response to increasingly unsuitable climate at their present habitats, rather than responses to short-term weather events. While several studies proposed an extinction debt associated with the persistence of high-elevation species, which delays species-specific responses to climate warming (Alexander et al. 2018; Dullinger et al. 2012) until their life spans are reached (Cotto et al. 2017), our findings indicate the onset of debt repayment through a progressing dieback at their lower range margins. Considering the second research question $i$, a consistent decrease in cover of each AR1 species reflects a continued trend also in the second decade, whereas such a pattern is less homogenous for species advancing from lower elevations.

The continued cover declines of the high-elevation specialists may have been caused either by direct climatic factors or by competitive displacement through advancing species from lower down. The overall decrease of vegetation cover, however, suggests that the shrinkage of AR1 species was faster than the expansion of other species (Fig. 2; Lamprecht et al. 2018). The majority of permanent plots on Schrankogel are located on raw soils, rock and scree, where species were found to be less exposed to competitive pressure, compared to habitats with developed soils rich on organic material (Kulonen et al. 2018). In turn, direct negative effects of warmer temperatures on cryophilic species through respiratory losses of carbohydrates are probable, if their limited capability to adapt respiration rates to higher temperatures, as reported for Cerastium uniflorum and Ranunculus glacialis (Cooper 2004; Körner 2003; Larigauderie and Körner 1995), holds true for the majority of AR1 species. Another more recent study found that higher temperatures cause increasing drought stress with negative effects on annual growth for Saxifraga oppositifolia in Spitsbergen (Opala-Owczarek et al. 2018). On Schrankogel, an increasing transformation towards a community composition adapted to drier soil conditions was indicated for the 20-year study period (Lamprecht et al. 2018).

High topographic variation of adjacent microhabitats was suggested to buffer effects of rising temperatures on local species survival (Scherrer and Körner 2011). The observed continued decrease in cover of all AR1 species in a large number of permanent plots, however, does not confirm this hypothesis. Thus, referring to research question iii, cold-adapted AR1 species tend to decrease slightly more in warmer plots, while species of AR2 and AR3 
showed higher cover increases in colder plots (Fig. 2). Although the latter increase could not keep pace with an overall decrease of AR 1 species, some common advancing species, such as Silene exscapa (AR2), may have exerted competitive pressure on AR1 species. In the baseline year 1994 , its total cover was well below that of the then most dominant species Saxifraga bryoides (AR1), but only 20 years later Silene exscapa was undisputedly the number one in terms of total cover (Fig. 1; Table 1, Tables S1, $\mathrm{S} 6, \mathrm{~S} 7)$. Several other AR2 species showed gains in cover, such as Festuca intercedens, Trisetum spicatum, Pedicularis aspleniifolia, and Erigeron uniflorus, but they are far less abundant than Silene exscapa.

The pronounced expansion and/or filling of six out of nine species associated with snowbed habitats was surprising, since higher temperatures should lead to earlier snow melt and, thus, to a shrinkage of snowbed habitats (Fig. 1; Table 1, Tables S1, S6, S7). Alpine snowbed species and communities are thought to be highly vulnerable to climate change effects (Björk and Molau 2007). They have been found to be affected by competition through encroaching taller-growing species from neighbouring communities in the subalpine to lower alpine zone in the Swiss Alps (Matteodo et al. 2016) and showed rapid reduction in growth performance when transplanted to alpine ridge habitats in New Zealand (Lord et al. 2018). In turn, increases of snowbed species' abundances were found in southern Norway in combination with increasing snow cover (Felde et al. 2012). A pan-European study, comparing historical and new alpine-subnival summit flora inventories, found an aboveaverage increase in the number of snowbed species on the summits (Grytnes et al. 2014), where an enforced melting of ice and snow patches, which liberates new habitats for colonisation, was suggested as explanation for the advance of snowbed species. Given that many of their summits were situated at the alpine-nival ecotone, our observations on Schrankogel could likely be additional evidence supporting their hypothesis. Subnival and nival environments, formerly mostly providing habitats for AR1 species only, which are capable of dealing with both low-temperature conditions and short growing seasons (Gottfried et al. 2002), are increasingly suitable for the less cold-adapted snowbed species.

An ongoing decline in cover of two AR3 graminoids, Carex curvula and Poa alpina was unexpected as well (Fig. 1, Fig. S2, Table 1, Tables S1, S6, S7), as both are common elements of alpine grassland vegetation, which should have shifted their distributions higher up. A similar decline of Carex curvula was observed by Cannone et al. (2007) and Cannone and Pignatti (2014) in the Italian Alps, who suggested negative effects of increased disturbance through permafrost degradation. We cannot test this hypothesis, although we observed an increasing surface destabilisation on Schrankogel.

\section{Limitations of the study}

While we are confident that our results are representative for ongoing vegetation changes across the alpine-nival ecotone, a number of limitations might have biased the observed species-specific changes. Such are a non-random study design, with permanent plots organised in transects. These were not homogenously distributed, which might have caused over- or underrepresentation of certain habitat types and species, but we accounted for the spatial structure inherent in the dataset by using permanent plots as random term in the GLMMs. Influences of ungulate herbivory by Capra ibex and additionally by sheep and goats in the lowermost plots cannot be excluded, but grazing signs were minor and impacts would not cause a directional change of plant species. Interference with concurrently changing patterns of soil microorganisms, micro- and mesofauna might have an influence on plant performance, but requires further studies. Another source of error might arise from inter-annual species fluctuation in phenology, which we attempted to minimise by resurveys in the same month in the peak growing season. Finally, observer errors unavoidably occur when using visual cover estimations. A recent study on observer variability, which included data from the Schrankogel permanent plots, indicated that observer errors did not exceed changes over time in cover, species turnover and the TI for observation periods $\geq 10$ years (Futschik et al. 2019).

\section{Conclusions}

The current study provides evidence of severe speciesspecific vegetation changes in permanent plots across the alpine-nival ecotone during the period 1994-2014 on Schrankogel. An overall increase in colonisations and a more pronounced increase in cover of most AR2 and lower elevational species in colder plots suggest a continued leadingedge expansion. The surprisingly prolific performance of most of the snowbed species may indicate the liberation of new microhabitats through an elongated snow-free period.

All subnival-nival AR1 species provide evidence of a rear-edge decline by showing the highest rates of disappearances combined with a consistent and strong decrease in cover, which was more pronounced in warmer plots. AR2 to AR4 species could not compensate these decreases, which points towards low levels of competition, but a continued maladaptation of high-elevation specialists to the current climate. Notably, this study revealed substantial differences between presence/absence and cover data. While, for example, only Poa laxa decreased in the number of occupied plots, all AR1 species declined consistently in cover. This underpins the importance of including species abundance data in studies analysing climate-driven vegetation changes. 
Acknowledgements Open access funding provided by University of Natural Resources and Life Sciences Vienna (BOKU). The GLORIA master site Schrankogel (and site of the LTSER Platform Tyrolean Alps) was established by Georg Grabherr, Michael Gottfried and Harald Pauli with support of the Austrian Federal Ministry of Science and Research and the International Geosphere Biosphere Programme (IGBP) through the Austrian Academy of Sciences. We thank the Government of Tyrol for providing the permission to set up a field camp for conducting the second resurvey of permanent plots and our colleagues Sophie Nießner, Andreas Berger, Veronika Fasching, Thomas Gassner, Christian Gilli, Claudia Gstöttl, David Paternoster, Norbert Sauberer, Simon Stifter, Hermann Stockinger, Michael Suen and Birgit Weis for their assistance, commitment and perseverance during the field season in 2014. We are grateful to Manfred Bardy-Durchhalter for the technical support with the database, to Lena Nicklas for statistical advice and to Barbara Friedmann and Estela Illa Bachs for helpful comments on the manuscript. We thank ZAMG for providing temperature and precipitation data from two high-elevation observatories (Brunnkogel, Sonnblick).

Author contributions HP, MW, AL and KS designed the study and were part of the recording team. KS, AL, PS and MW analysed the output data. HP managed the study. KS, AL and HP wrote the manuscript. All authors discussed the results and implications and commented on the manuscript at all stages.

Funding This study was funded by the Austrian Climate Research Programme (ACRP 6: GZ B368633, KR13AC6K11076).

\section{Compliance with ethical standards}

Conflict of interest The authors declare that they have no conflict of interest.

Ethical approval This study does not involve research on human participants or animals.

Informed consent Informed consent was obtained from all individual participants included in the study.

Open Access This article is distributed under the terms of the Creative Commons Attribution 4.0 International License (http://creativeco mmons.org/licenses/by/4.0/), which permits unrestricted use, distribution, and reproduction in any medium, provided you give appropriate credit to the original author(s) and the source, provide a link to the Creative Commons license, and indicate if changes were made.

\section{References}

Alexander JM, Chalmandrier L, Lenoir J et al (2018) Lags in the response of mountain plant communities to climate change. Glob Change Biol 24:563-579. https://doi.org/10.1111/gcb.13976

Bates D, Maechler M, Bolker BM, Walker S (2015) 1me4: linear mixed-effects models using Eigen and S4. J Stat Softw 67:1-48. https://doi.org/10.18637/jss.v067.i01

Bertuzzo E, Carrara F, Mari L, Altermatt F, Rodriguez-Iturbe I, Rinaldo A (2016) Geomorphic controls on elevational gradients of species richness. Proc Natl Acad Sci 113:1737-1742. https:// doi.org/10.1073/pnas.1518922113

Björk R, Molau U (2007) Ecology of alpine snowbeds and the impact of global change. Arct Antarct Alp Res 39:34-43. https://doi. org/10.1657/1523-0430(2007)39\%5b34:EOASAT\%5d2.0.CO;2
Brooks ME, Kristensen K, van Benthem KJ et al (2017) GlmmTMB balances speed and flexibility among packages for zero-inflated generalized linear mixed modeling. R J 9:378-400

Cannone N, Pignatti S (2014) Ecological responses of plant species and communities to climate warming: upward shift or range filling processes? Clim Change 123:201-214. https://doi.org/10.1007/ s10584-014-1065-8

Cannone N, Sgorbati S, Guglielmin M (2007) Unexpected impacts of climate change on alpine vegetation. Front Ecol Environ 5:360-364. https://doi.org/10.1890/1540-9295(2007)5\%5b360 :UIOCCO \% 5d2.0.CO;2

Cannone N, Diolaiuti G, Guglielmin M, Smiraglia C (2008) Accelerating climate change impacts on alpine glacier forefield ecosystems in the European Alps. Ecol Appl 18:637-648. https:// doi.org/10.1890/07-1188.1

Carilla J, Halloy S, Cuello S, Grau A, Malizia A, Cuesta F (2018) Vegetation trends over eleven years on mountain summits in NW Argentina. Ecol Evol 8:11554-11567. https://doi. org/10.1002/ece 3.4602

Chen IC, Hill JK, Ohlemuller R, Roy DB, Thomas CD (2011) Rapid range shifts of species associated with high levels of climate warming. Science 333:1024-1026. https://doi.org/10.1126/scien ce. 1206432

Cooper EJ (2004) Out of sight, out of mind: thermal acclimation of root respiration in Arctic Ranunculus. Arct Antarct Alp Res 36:308-313. https://doi.org/10.1657/15230430(2004)036\%5b0308:OOSOOM\%5d2.0.CO;2

Cotto O, Wessely J, Georges D et al (2017) A dynamic eco-evolutionary model predicts slow response of alpine plants to climate warming. Nat Commun 8:9. https://doi.org/10.1038/ncomm s15399

Cribari-Neto F, Zeileis A (2010) Beta regression in R. J Stat Softw 34:1-24. https://doi.org/10.18637/jss.v034.i02

Dullinger S, Gattringer A, Thuiller W et al (2012) Extinction debt of high-mountain plants under twenty-first-century climate change. Nat Clim Change 2:619-622. https://doi.org/10.1038/ nclimate 1514

Engler R, Randin C, Thuiller W et al (2011) 21st century climate change threatens mountain flora unequally across Europe. Glob Change Biol 17:2330-2341. https://doi.org/10.111 1/j.1365-2486.2010.02393.x

Erschbamer B, Unterluggauer P, Winkler E, Mallaun M (2011) Changes in plant species diversity revealed by long-term monitoring on mountain summits in the Dolomites (northern Italy). Preslia 83:387-401

Evangelista A, Frate L, Carranza ML, Attorre F, Pelino G, Stanisci A (2016) Changes in composition, ecology and structure of highmountain vegetation: a re-visitation study over 42 years. AoB Plants 8:11. https://doi.org/10.1093/aobpla/plw004

Felde VA, Kapfer J, Grytnes JA (2012) Upward shift in elevational plant species ranges in Sikkilsdalen, central Norway. Ecography 35:922-932. https://doi.org/10.1111/j.1600-0587.2011.07057.x

Fischer MA, Oswald K, Adler W (2008) Exkursionsflora für Österreich, Liechtenstein und Südtirol, 3rd edn. Biologiezentrum der Oberösterreichischen Landesregierung, Linz

Flatscher R, Garcia PE, Hülber K et al (2015) Underestimated diversity in one of the world's best studied mountain ranges: the polyploid complex of Senecio carniolicus (Asteraceae) contains four species in the European Alps. Phytotaxa 213:21. https:// doi.org/10.11646/phytotaxa.213.1.1

Freeman BG, Lee-Yaw JA, Sunday JM, Hargreaves AL (2018) Expanding, shifting and shrinking: the impact of global warming on species' elevational distributions. Glob Ecol Biogeogr 27:1268-1276. https://doi.org/10.1111/geb.12774

Futschik A, Winkler M, Steinbauer K, Lamprecht A, Rumpf SB, Barančok P, Palaj A, Gottfried M, Pauli H (2019) Disentangling 
observer error and climate change effects in long-term monitoring of alpine plant species composition and cover. J Veg Sci. https://doi.org/10.1111/jvs.12822

Giménez-Benavides L, Escudero A, García-Camacho R, GarcíaFernández A, Iriondo JM, Lara-Romero C, Morente-López J (2018) How does climate change affect regeneration of Mediterranean high-mountain plants? An integration and synthesis of current knowledge. Plant Biol 20:50-62

Gottfried M, Pauli H, Reiter K, Grabherr G (2002) Potential effects of climate change on alpine and nival plants in the Alps. In: Körner C, Spehn EM (eds) Mountain biodiversity-a global assessment. Parthenon Publishing, London, pp 213-223

Gottfried M, Pauli H, Futschik A et al (2012) Continent-wide response of mountain vegetation to climate change. Nat Clim Change 2:111-115

Grabherr G, Gottfried M, Pauli H (1994) Climate effects on mountain plants. Nature 369:448

Grytnes JA, Kapfer J, Jurasinski G et al (2014) Identifying the driving factors behind observed elevational range shifts on European mountains. Glob Ecol Biogeogr 23:876-884. https://doi. org/10.1111/geb.12170

Hammer W, Ohnesorge T, Sander B, Kerner-Marilaun F (1929) Geologische Spezialkarte der Republik Österreich, 1:75.000, Blatt 5146, Ötzthal. Geologische Bundesanstalt, Wien, Austria

Hothorn T, Bretz F, Westfall P (2008) Simultaneous inference in general parametric models. Biom J 50:346-363. https://doi. org/10.1002/bimj.200810425

Körner C (2003) Alpine plant life: functional plant ecology of high mountain ecosystems, 2nd edn. Springer, Berlin

Kulonen A, Imboden RA, Rixen C, Maier SB, Wipf S (2018) Enough space in a warmer world? Microhabitat diversity and small-scale distribution of alpine plants on mountain summits. Divers Distrib 24:252-261. https://doi.org/10.1111/ddi.12673

Kuznetsova A, Brockhoff PB, Christensen RHB (2016) lmerTest: tests in linear mixed effects models. $\mathrm{R}$ package version 2.0-30

Ladinig U, Hacker J, Neuner G, Wagner J (2013) How endangered is sexual reproduction of high-mountain plants by summer frosts? Frost resistance, frequency of frost events and risk assessment. Oecologia 171:743-760

Lamprecht A, Semenchuk PR, Steinbauer K, Winkler M, Pauli H (2018) Climate change leads to accelerated transformation of high-elevation vegetation in the central Alps. New Phytol 220:447-459. https://doi.org/10.1111/nph.15290

Larigauderie A, Körner C (1995) Acclimation of leaf dark respiration to temperature in alpine and lowland plant-species. Ann Bot $76: 245-252$

Lenoir J, Svenning JC (2015) Climate-related range shifts-a global multidimensional synthesis and new research directions. Ecography 38:15-28. https://doi.org/10.1111/ecog.00967

Lesica P (2014) Arctic-alpine plants decline over two decades in Glacier National Park, Montana, USA. Arct Antarct Alp Res 46:327332. https://doi.org/10.1657/1938-4246-46.2.327

Lord JM, Mark AF, Humar-Maegli T, Halloy SRP, Bannister P, Knight A, Dickinson KJM (2018) Slow community responses but rapid species responses 14 years after alpine turf transplantation among snow cover zones, south-central New Zealand. Perspect Plant Ecol Evol Syst 30:51-61. https://doi.org/10.1016/j.ppees 2017.07.004

Lüdecke D (2018) ggeffects: Tidy data frames of marginal effects from regression models. J Open Source Softw 3:772. https://doi. org/10.21105/joss.00772

Mangiafico S (2018) rcompanion: Functions to support extension education program evaluation. $\mathrm{R}$ package version 1.13.2. http://doi. org/10.1007/s00704-012-0584-3
Marty C, Meister R (2012) Long-term snow and weather observations at Weissfluhjoch and its relation to other high-altitude observatories in the Alps. Theoret Appl Climatol 110:573-583. https://doi. org/10.1007/s00704-012-0584-3

Matteodo M, Ammann K, Verrecchia EP, Vittoz P (2016) Snowbeds are more affected than other subalpine-alpine plant communities by climate change in the Swiss Alps. Ecol Evol 6:6969-6982. https://doi.org/10.1002/ece3.2354

Mirtl M, Bahn M, Battin T et al (2015) Forschung für die Zukunft LTER-Austria White Paper 2015 zur Lage und Ausrichtung von prozessorientierter Ökosystemforschung, Biodiversitäts- und Naturschutzforschung sowie sozio-ökologischer Forschung in Österreich, vol 2. LTER-Austria Schriftenreihe, Wien

Opala-Owczarek M, Piroznikow E, Owczarek P et al (2018) The influence of abiotic factors on the growth of two vascular plant species (Saxifraga oppositifolia and Salix polaris) in the High Arctic. CATENA 163:219-232. https://doi.org/10.1016/j.caten a.2017.12.018

Parmesan C, Yohe G (2003) A globally coherent fingerprint of climate change impacts across natural systems. Nature 421:37-42. https ://doi.org/10.1038/nature01286

Pauli H, Gottfried M, Reiter K, Klettner C, Grabherr G (2007) Signals of range expansions and contractions of vascular plants in the high Alps: observations (1994-2004) at the GLORIA mastersite Schrankogel, Tyrol, Austria. Glob Change Biol 13:147-156. https ://doi.org/10.1111/j.1365-2486.2006.01282.x

Pauli H, Gottfried M, Dullinger S et al (2012) Recent plant diversity changes on Europe's mountain summits. Science 336:353-355. https://doi.org/10.1126/science.1219033

Rumpf SB, Hülber K, Klonner G et al (2018) Range dynamics of mountain plants decrease with elevation. Proc Natl Acad Sci USA 115:1848-1853. https://doi.org/10.1073/pnas.1713936115

Scherrer D, Körner C (2011) Topographically controlled thermalhabitat differentiation buffers alpine plant diversity against climate warming. J Biogeogr 38:406-416. https://doi.org/10.111 1/j.1365-2699.2010.02407.x

Smithson M, Verkuilen J (2006) A better lemon squeezer? Maximumlikelihood regression with beta-distributed dependent variables. Psychol Methods 11:54-71

Steinbauer MJ, Grytnes JA, Jurasinski G et al (2018) Accelerated increase in plant species richness on mountain summits is linked to warming. Nature 556:231-234. https://doi.org/10.1038/s4158 6-018-0005-6

Tackenberg O, Stöcklin J (2008) Wind dispersal of alpine plant species: a comparison with lowland species. J Veg Sci 19:109-118. https ://doi.org/10.3170/2007-8-18338

R Core Team (2018) R: a language and environment for statistical computing. R foundation for statistical computing. http://www.R-proje ct.org/. Accessed 16 Sept 2019

Walther GR, Beissner S, Burga CA (2005) Trends in the upward shift of alpine plants. J Veg Sci 16:541-548. https://doi. org/10.1111/j.1654-1103.2005.tb02394.x

Wickham H (2016) ggplot2: Elegant graphics for data analysis. Springer, New York

Wipf S, Stöckli V, Herz K, Rixen C (2013) The oldest monitoring site of the Alps revisited: accelerated increase in plant species richness on Piz Linard summit since 1835. Plant Ecol Div 6:447-455. https ://doi.org/10.1080/17550874.2013.764943

Publisher's Note Springer Nature remains neutral with regard to jurisdictional claims in published maps and institutional affiliations. 